\title{
Modified Laterally Flap Technique for Root Coverage of Thin Gin- gival Phenotype: A Case Report
}

\section{Davi da Silva Barbirato ${ }^{1,2 *}$, Natália Rodrigues Manes 3 , Victor de Macedo Varela ${ }^{3}$, Otto de Oliveira Magro $^{3}$, Mariana Fampa Fogacci ${ }^{2}$ and Maria Cynésia Medeiros de Barros ${ }^{4}$}

\author{
${ }^{1}$ Periodontist, Stomatologist, Maxillofacial Surgeon, D.D.S, External Advisor in Professional Master's Degree, Federal \\ University of Rio de Janeiro (UFRJ), Brazil \\ ${ }^{2}$ Post-Doctoral Researcher, Federal University of Rondonia (UNIR), Brazil \\ ${ }^{3}$ Federal University of Rio de Janeiro (UFRJ), Brazil \\ ${ }^{4}$ Assistant Professor, School of Dentistry, Federal University of Rio de Janeiro (UFRJ), Brazil
}

*Corresponding author: Davi da Silva Barbirato, Periodontist, Stomatologist, Maxillofacial surgeon, D.D.S., Post-Doctoral Researcher, External Advisor in Professional Master's Degree, Federal University of Rondonia (UNIR), BR 364, Km 9.5, Acre Direction, CEP 76800-000, Porto Velho, Rondonia, RO, Brazil, Tel: +(55)-(69)-21822122, E-mail: davibarbirato@gmail.com

\begin{abstract}
The aim of this study was to propose a new modified lateral positioned flap for root coverage of unfavorable gingival phenotype. The patient reported a dentine hypersensitivity and esthetic complaint in tooth 41 related to the gingival recession: "U"-shaped gingival contour, class II and type IV periodontium of "Miller" and "Maynard \& Wilson" classifications, respectively. There was neither accident nor surgical complications. We observed a creeping reattachment between 3 and 6 months postoperative with an increasing in the periodontal attachment during the 18 months of follow-up. Total root coverage and the complete remission of dentin hypersensitivity were achieved.
\end{abstract}

\section{Keywords}

Gingival recession, Modified lateral positioned flap, Mucogingival flap, Periodontal aesthetics, Root coverage

\section{Introduction}

Gingival recession is characterized by apical migration of the gingival margin in relation to the cement-enamel junction resulting in root exposure of one or more teeth, which may be localized or generalized [1]. Its etiology is multifactorial and may be associated with local mechanical and inflammatory factors, to the morphology of the periodontium, to iatrogeny, to orthodontic therapy and occlusal trauma; however, it is not yet agreed that or- thodontic treatment and occlusal trauma are etiological factors for gingival recessions [2-6]. The dental plaque and the consequent periodontal diseases, accompanied by clinical attachment loss, besides the local mechanical trauma, are primary etiological factors of gingival recessions. Among the secondary etiological risk factors, there are periodontitis risk factors, alveolar bone dehiscences and fenestrations. The amount of attached gingiva and the thickness of alveolar bone and gingival tissue can be considered as predisposing factors for gingival recessions too [3-6]. Main causes of recessions includes buccal tipped teeth, rotation teeth and tissue injury due to inadequate cleaning or parafunctional habits $[5,6]$. Also, there is a direct relationship between age and root exposure [7].

The main complaint of patients with gingival recession includes esthetic, dentine hypersensitivity, plaque and dental calculus deposits often associated with local inflammation, decay, erosion and abrasion [6].

The gingival recession is well defined by three major classifications [8,9]. Miller classes I and II offer greater predictability of corrective surgical treatments, but the surgical technique, the ability of the operator and behavioral factors still directly influence the postoperative period and the final result [8].

Citation: Barbirato DS, Manes NR, Varela VM, Magro OO, Fogacci MF, et al. (2017) Modified Laterally Flap Technique for Root Coverage of Thin Gingival Phenotype: A Case Report. Int J Oral Dent Health 3:041. doi.org/10.23937/2469-5734/1510041

Received: January 04, 2017: Accepted: April 04, 2017: Published: April 07, 2017

Copyright: (c) 2017 Barbirato DS, et al. This is an open-access article distributed under the terms of the Creative Commons Attribution License, which permits unrestricted use, distribution, and reproduction in any medium, provided the original author and source are credited. 


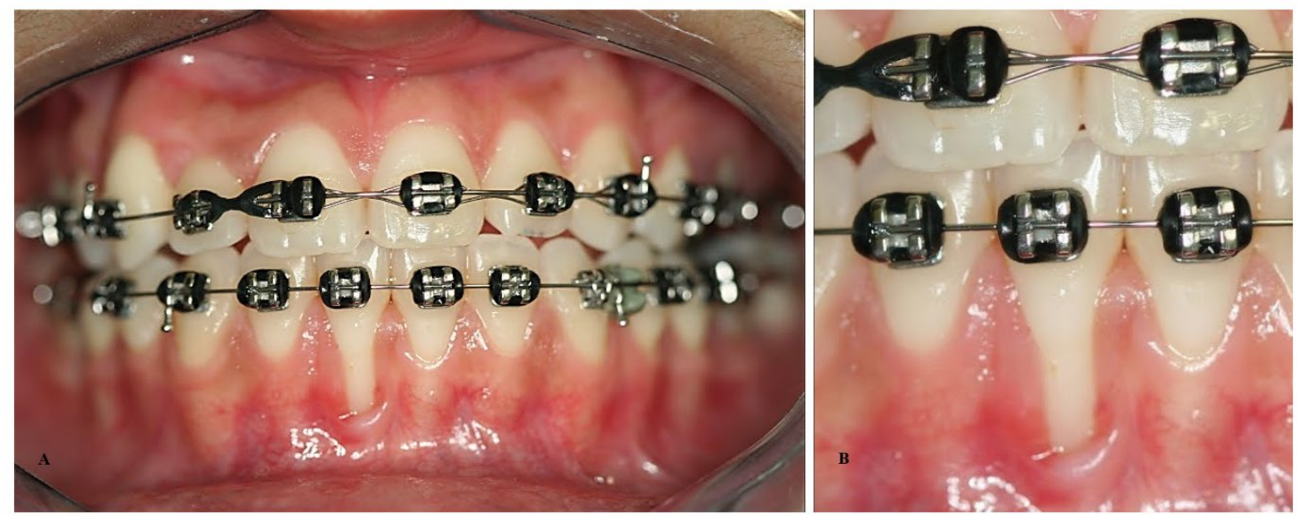

Figure 1: Initial clinical photographs A) gingival recession on tooth 41; B) detail of the gingival contour, root surface exhibition and cemento-enamel junction.

Pedicle graft was initially described as laterally positioned flap for root coverage [10]. It provides an increasing height of the gingival margin by the creeping attachment in the initial postoperative months. The bone exposure in the donor site and the use of periodontal dressings for 14 days are disadvantages of this technique $[11,12]$.

The use of sub epithelial connective tissue optimizes the thickness gain in the grafted area and increases the predictability of success in root coverage surgeries. So, the literature indicates it as the gold standard in surgical treatment of gingival recession [13]. This technique requires a partial-thickness flap. However, patients with very thin gingival phenotype are still a major challenge due to the difficulty or impossibility of gingival tissue dissection, risk of fenestration and insufficient blood supply $[14,15]$.

This case report aims to propose a new modified laterally positioned flap technique for the root coverage in patients with unfavorable gingival phenotype.

\section{Report}

This article reports a case of a female patient, 22-yearold, attended at the Dental School of the Federal University of Rio de Janeiro. She complained of a dentine hypersensitivity and aesthetic involvement related to tooth 41 . The periodontal clinical examination revealed a gingival recession possibly associated with the lower lip frenulum, surgically removed previously (Figure 1). The patient was systemically healthy and reported not to use any medication or orthodontic treatment in the last 12 months. Neither parafunctional habits nor mechanical traumas were associated with the cause.

The periodontal clinical examination was conducted at six sites per tooth [16] and 12 parameters were assessed: gingival bleeding [17], bleeding on probing [18], visible dental plaque [17], dental calculus [19], probing pocket depth, clinical attachment level, bone dehiscence by transgingival probing [20], tooth mobility, integrity of the root surface at gingival recession, morphology of the cement-enamel junction, preservation of interdental papillae, attached gingiva and lower lip frenulum insert. The interdental bone integrity was evaluated in periapical radiographs for ridge resorption. Also, we described the gingival recession morphology based on the three major classifications $[8,21,22]$. The thickness of keratinized tissue was measured penetrating the periodontal probe on gingival tissue $90^{\circ}$ in relation to the underlying bone surface, under local anesthesia.

The clinical examination revealed a " $U$ "-shaped gingival recession [21] and Miller's class II recession [8]. It was morphologically classified as periodontal type IV because the thickness of the keratinized tissue measured about $1 \mathrm{~mm}$ in the presence of buccal bone dehiscence [22]. The height and the width of gingival recession were $5 \mathrm{~mm}$ (CAL) and $3 \mathrm{~mm}$ in the buccal periodontal site, respectively (Figure 1 and Figure 2). There were no periodontal pockets or impairment of bone crests in any interproximal periodontal site. However, we identified a buccal bone dehiscence in the tooth 41 by the transgingival probing [20] and the morphology of the gingival recession [23].

Just a few periodontal sites exhibited gingivitis and no periodontal pockets were observed [24]. There was no significant accumulation of plaque or dental calculus in the root surface exposed by the gingival recession. We observed a gingival bleeding and bleeding on probing in the proximal sites from 42 and 43 teeth, but all other periodontal sites involved in flap were healthy. The exposed root surface exhibited no carious lesions or significant wear. This tooth had no mobility. The papillae filled all the interproximal space to the contact points and no black space was diagnosed.

The frenectomy indication was defined based on the proximity of the lower lip frenulum insert with the contour of the gingival recession of tooth 41 and operated previously to the root coverage surgery (approximately three months), to prevent a possible flap tension and to reduce the chance of failure [25]. The orthodontic treatment was suspended during adequacy of the oral envi- 


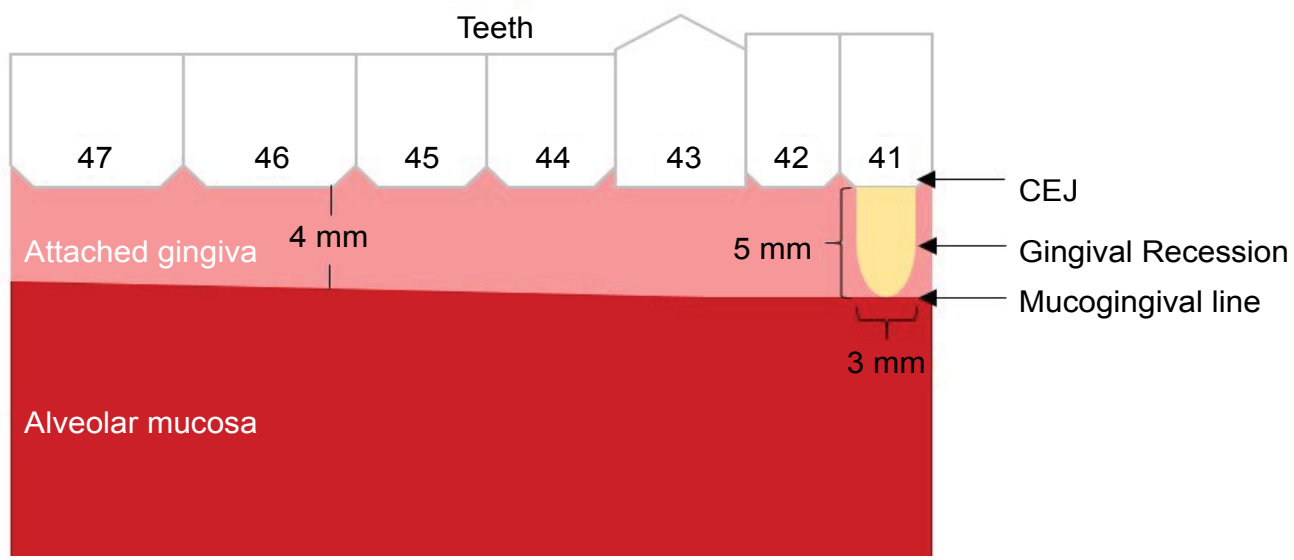

Figure 2: Illustration of the gingival recession: distance of $5 \mathrm{~mm}$ between the CEJ and the gingival margin (Gingival Recession).

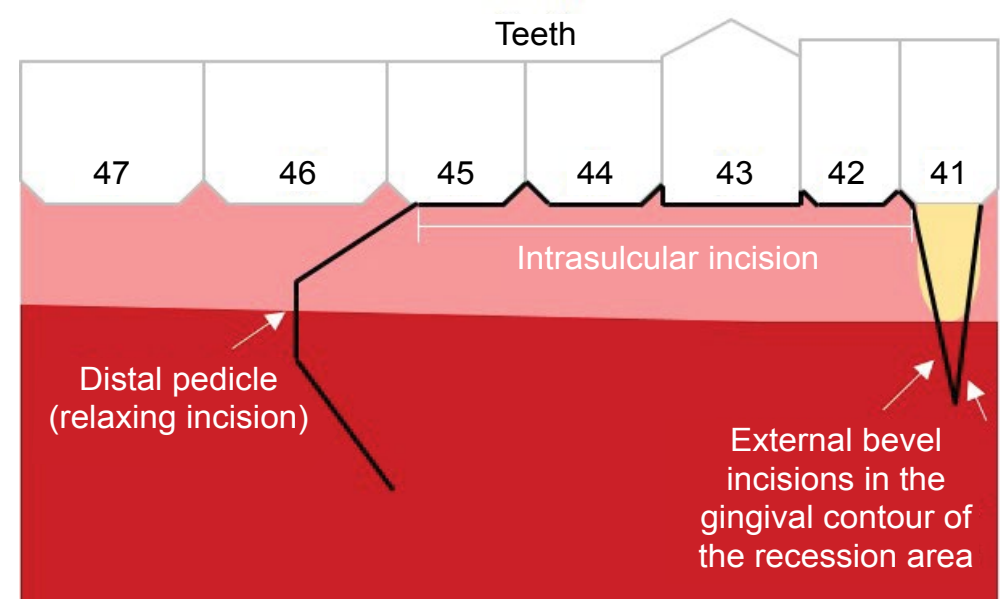

Figure 3: Illustration of the lateral flap proposed: incision contour in black.

ronment, before the periodontal surgery, and returned a month and a half after surgery. The basic periodontal therapy is a fundamental condition for the performance of elective periodontal surgeries. The orthodontic movement was suspended to stabilize the periodontal tissues regarding the bone remodeling and the consequent local inflammatory events. It could contribute to the predictability of the case $[4,26]$.

The surgeries were conducted in the absence of visible dental plaque [17], dental calculus [19], gingival bleeding [17] and bleeding on probing [18] of the periodontal tissues involved in the flap. This condition was achieved by professional cleaning and oral hygiene instruction. We advised the patient to implement teeth cleaning with a post-surgical brush for 30 days after the surgery (TePe ${ }^{\circledR}$ Special Care, TePe Munhygien produkter AB, Malmö, Sweden), and complement with a local application of $0.2 \%$ chlorhexidine gel bioadhesive 3 times per day, during 14 days (Perioxidin ${ }^{\circledR}$ Gel, Lacer, SA, Spain), to prevent the biofilm formation [27-29].

Preoperative medication prescription consisted of 2 g amoxicillin (Amoxi ${ }^{\circledR} 500 \mathrm{mg}$ BD, GlaxoSmithKline Brasil Ltda, Rio de Janeiro, RJ, Brasil) and $8 \mathrm{mg}$ dexamethasone (Decadron ${ }^{\circledR} 4$ mg, EMS/SA, São Bernardo do Campo, SP,
Brazil), 1 and 2 hours before surgery, respectively. Mouth rinsing with chlorhexidine digluconate $0.12 \%$ (Perioxidin ${ }^{\circledR}$, Lacer, SA, Spain) began 48 hours prior to surgery, every 12 hours, 30 minutes after teeth brushing.

Surgical procedures performed were: 1) local anesthesia using lidocaine hydrochloride $2 \%$ with epinephrine 1:200,000 (ALPHACAINE ${ }^{\circledR} 100$, DFL, Rio de Janeiro, RJ, Brazil), 2) teeth prophylaxis and mouth rinse with $0.12 \%$ chlorhexidine 30 minutes later (Perioxidin ${ }^{\circledR}$, Lacer, SA, Spain), 3) supragingival scaling and root planning, 4) connective tissue exposure in the gingival recession contour with twoline vertical incisions, apically extended, 5) intra-sulcular incision from the mesial of the tooth 41 to the distal of the tooth 45 (Figure 3), 6) one-line vertical incision extended to the free mucosa from the distal of tooth 45 , preserving its distal papilla and including part of the keratinized tissue of tooth 46 (Figure 3), 7) detachment of a full-thickness flap until the mucogingival limit, 8) tissue dissection underlying connective tissue of the free mucosa (undermining) to promote a passive flap stabilization in the receptor area, 9) flap synthesis with 4-0 silk suture (Ethicon ${ }^{\circledR}$, Johnson \& Johnson professional products Ltda, Rio de Janeiro, RJ, Brazil) by interrupted simple sutures in vertical incisions, interpapillary sutures in all teeth engaged and 


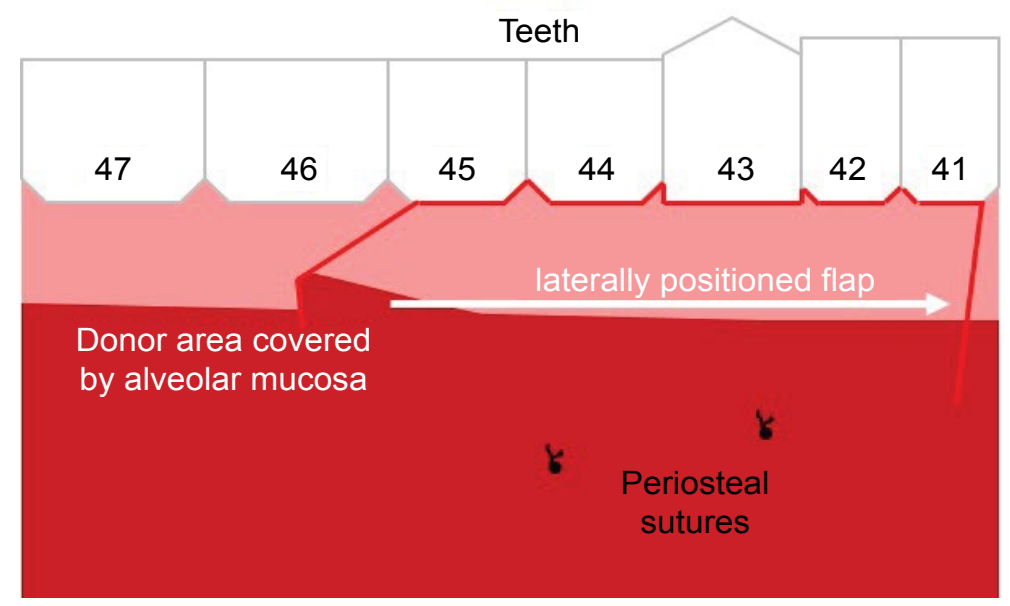

Figure 4: Illustration of the laterally positioned flap proposed.

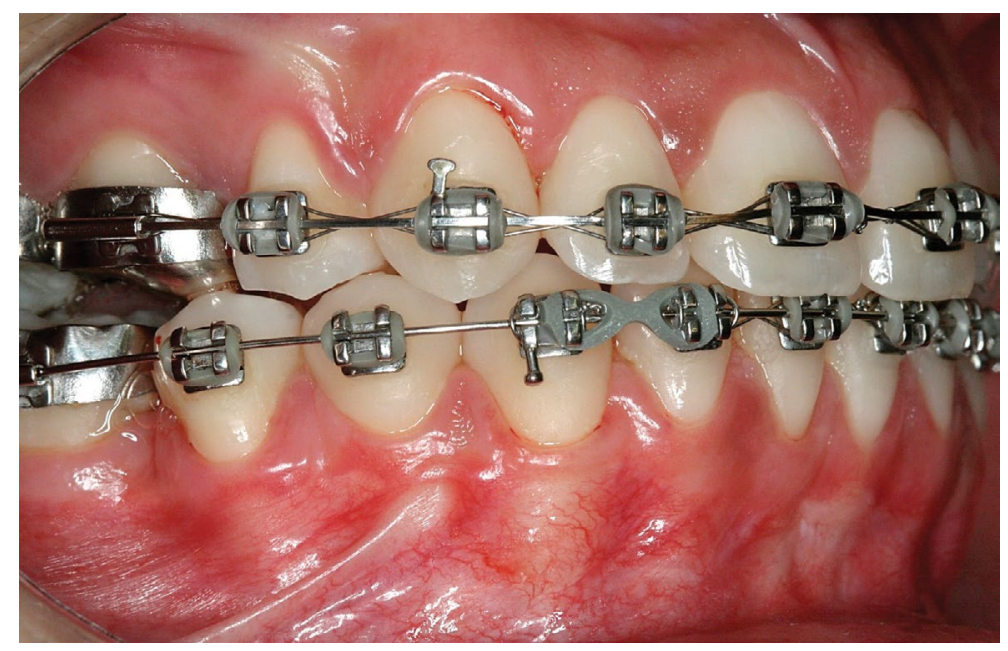

Figure 5: Photo of the postoperative donor site (9 postoperative months).

periosteal sutures to prevent an unexpected flap displacement (Figure 4), 10) dissection underlying connective tissue of the free mucosa (undermining) in tooth 46 to promote the primary closure of the donor region distal to the laterally positioned flap (Figure 4 and Figure 5), 11) a tender digital pressure with a sterile moist gauze for 5 minutes, to eliminate possible voids. The sutures were removed 14 days after surgery because of the extent of the flap displaced laterally, the thickness of this tissue and the length of the gingival recession. The displacement of the margins of the flap could compromise the aesthetic and functional results [11,12,14,30].

The sub periosteal detachment of gingival tissue at the flap offered a very safe tissue manipulation and made a tension free stabilization possible at the receiving area of the graft. Such procedure and the variation in the contour of the distal vertical relaxing incision can be considered the main advantage of this technique when compared to the classic laterally positioned flap (Figure 3). The donor area distal to the laterally positioned flap maintained $3 \mathrm{~mm}$ of a thin attached gingiva to preserve the periodontal integrity and health of the 46 teeth. The new flap design we used promoted a more conservative tissue manipulation in the tooth 46 preserving an important zone of intact attached gingiva and allowed the displacement of a $2 \mathrm{~mm}$ band of keratinized mucosa to the tooth 45 cervical margin.

Postoperative medication prescription consisted of 1 g amoxicillin (Amoxil ${ }^{\circledR} 500$ mg BD, GlaxoSmithKline Brasil Ltda, Rio de Janeiro, RJ, Brasil) and $4 \mathrm{mg}$ dexamethasone (Decadron ${ }^{\circledR} 4 \mathrm{mg}$, EMS/SA, São Bernardo do Campo, SP, Brazil), every 8 hours and a single dose 24 hours after surgery, respectively. $1 \mathrm{~g}$ dipyrone monohydrate (Novalgina ${ }^{\circledR}$, Sanofi-aventis Farmacêutica Ltda, Suzano, SP, Brazil) was prescribed at intervals of 6 hours for up to 5 days. Mouth rinsing with chlorhexidine digluconate $0.12 \%$ (Perioxidin ${ }^{\circledR}$, Lacer, SA, Spain) was maintained two times a day for 14 days.

The patient was kept on a monthly oral hygiene monitoring and professional plaque control. The evolution of the surgical wound repair was performed weekly for the first month, from 15 to 15 days in the second month and monthly for 18 months. There was no accumulation of plaque or dental calculus, suppuration or clinical signs of local trauma. The redness and swelling ceased completely about the twentieth postoperative day. After this period, no signs or clinical symptoms of gingivitis or periodontitis were diagnosed in the periodontal follow-up consultations. 
Clinical photographs of longitudinal follow-up suggest stability of the gingival margin in all teeth involved in the flap. The grafted area maintained a normochromic and a normal tissue texture without presence of any
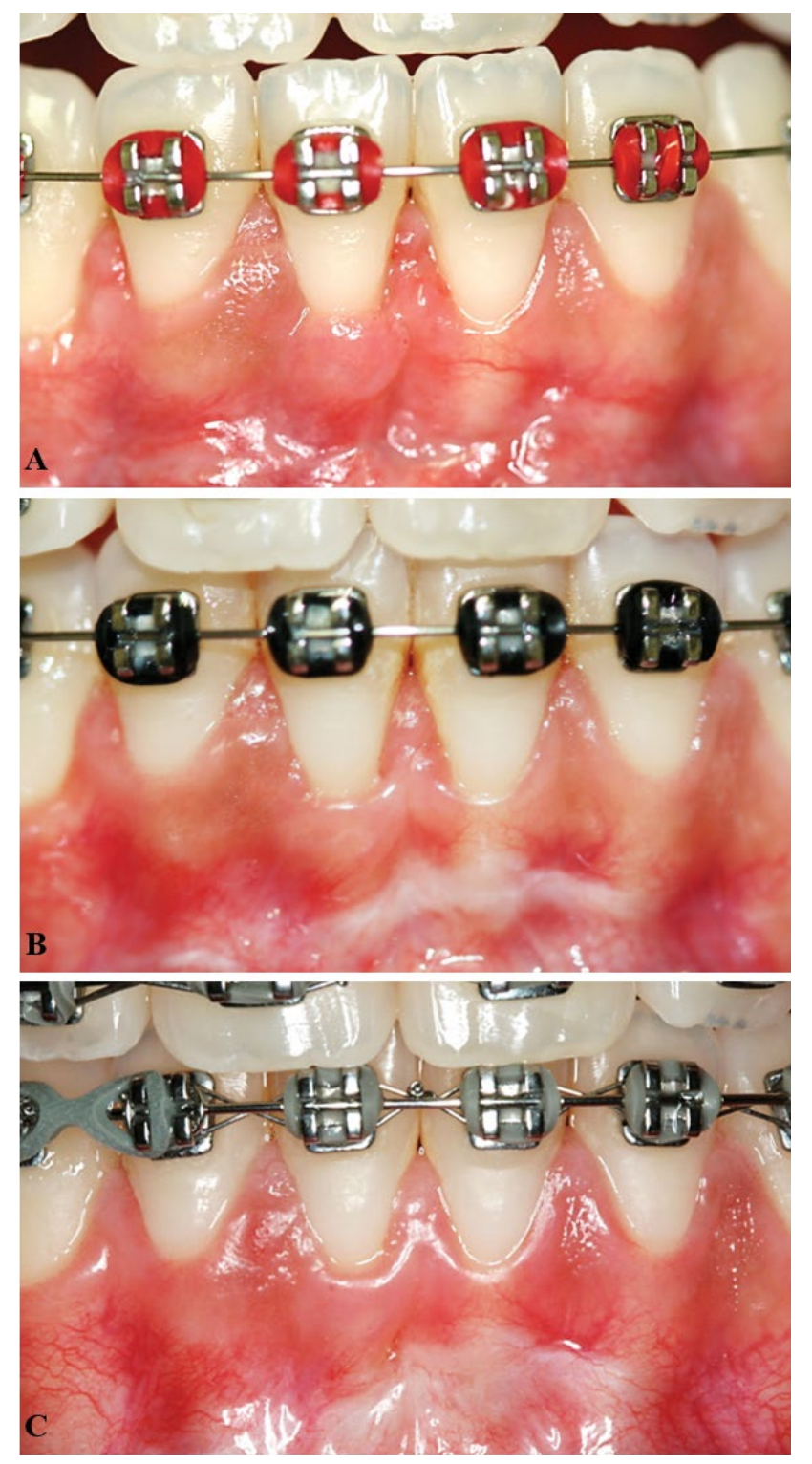

Figure 6: Postoperative clinical photographs A) 3 postoperative months; B) 6 postoperative months; C) 9 postoperative months. periodontal disease. We observed just a small exposure of cement-enamel junction $(1 \mathrm{~mm})$ in the mesial periodontal site of the tooth 41 at 3, 6 and 9 months postoperative (Figure 6).

Over the period of 18 months, none of the clinical periodontal parameters evaluated were positive for plaque and dental calculus presence or clinical signs of periodontal disease. Probing pocket depth measurements were $\leq 3 \mathrm{~mm}$ for all periodontal sites related to the flap, which suggests the formation of a new insertion instead of a long junctional epithelium. We also concluded that there was a continued benefit of root coverage done because of a late gain observed in the mesial of tooth 41 resulting in a complete covering of cement-enamel junction (Figure 7). This result can be explained by the creeping attachment [31,32].

The teeth photograph at the completion of orthodontic treatment reflects a healthy and harmonic mucosa at the operated area, indicating the success of the technique (Figure 7). The patient reported no pain, no gingival bleeding, no more sensitivity in the tooth 41 and was satisfied with the aesthetic results achieved.

\section{Discussion}

The gingival recession of tooth 41 was probably associated with its position (buccally) and consequent bone dehiscence. The tension exerted by the high lower lip frenulum insert may have contributed to the apical migration of the gingival margin $[4,33]$.

The relationship between frenulum and the etiology of gingival recessions is controversial, but it may play an important role in this process contributing in favorable cases to apical migration of the gingival margin and hindering local hygiene when by the proximity with teeth cervical areas $[14,33]$. The gingival tissue in areas of gingival recession and near the lower labial frenulum, often presents an indicative of local tissue inflammation associated with plaque and dental calculus (bleeding), but also clinical signs and symptoms of inflammation related to a constant mechanical local trauma [7]. From that, we decided to perform frenectomy in a first surgical time.
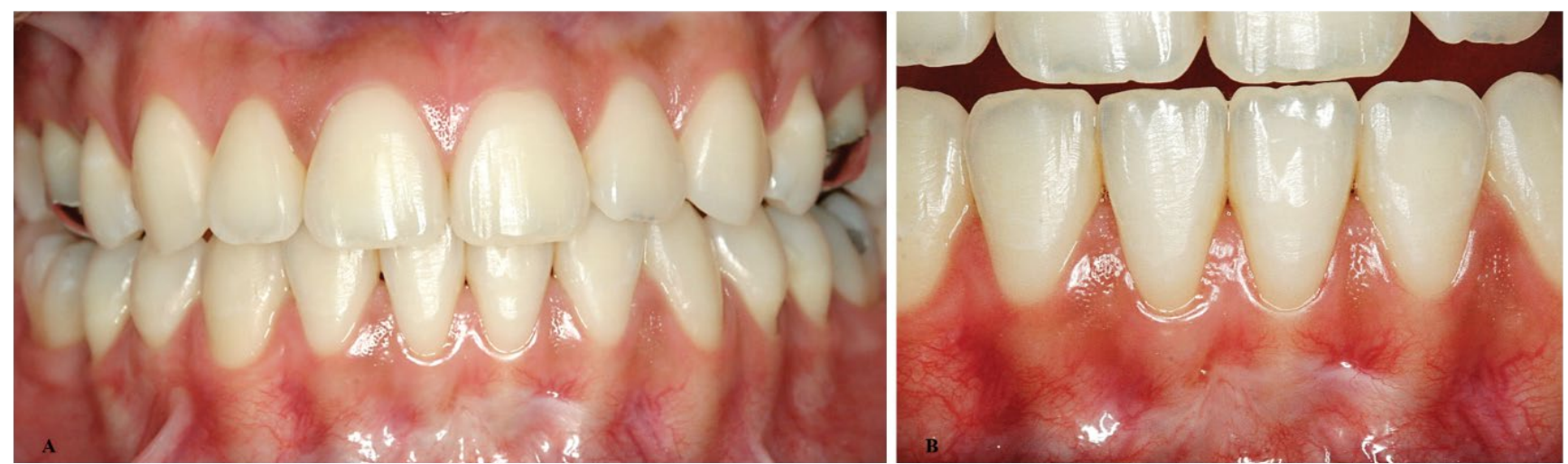

Figure 7: Tissue stability 18 months after root coverage: A) aesthetic results achieved; B) normochromic and stable gingiva and total root surface covering. 


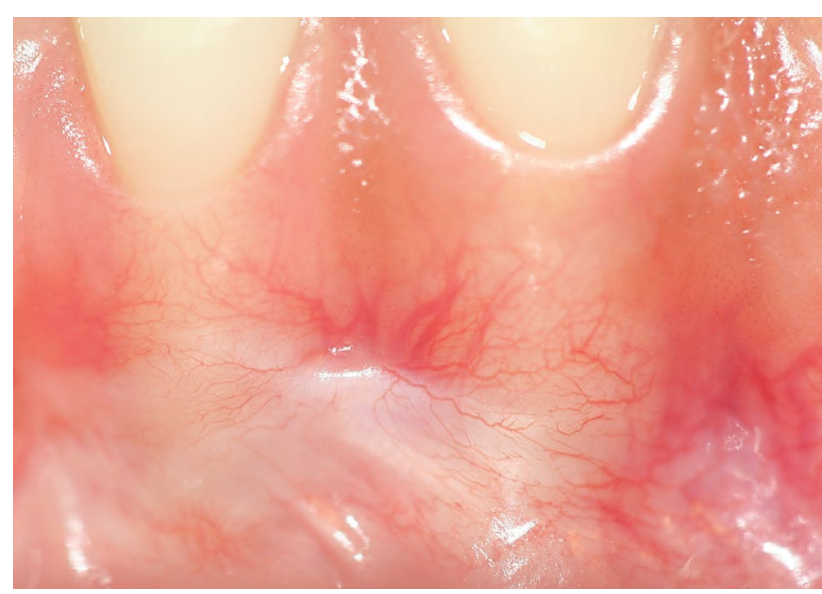

Figure 8: Satisfactory contour of the gingival margin and the transparency of the coating mucosa resulting from the gingival phenotype 18 months after root coverage.

As for the dimensions of gingival recessions, literature indicates width as more critical than height for root coverage surgeries [34]. In this case, the height of the exposed root was $5 \mathrm{~mm}$ and the width was about $3 \mathrm{~mm}$. The predictable success for root coverage surgeries, according to Miller [8], is higher in classes I and II. The shape of the gingival recession contour can also influence the success of reconstructive surgeries. The " $U$ "-shape tends to have poor prognosis when compared to " $\mathrm{V}$ " or "I"-shapes [21]. The thickness of the gingival tissue also impacts mucogingival surgeries. A type IV periodontium [8] is more associated to gingival recessions and worse prognosis of root coverage [35]. It also limits a partial-thickness flap execution. For those cases, a full-thickness flap could minimize the chance of surgical accidents and complications, morbidity, and reduce the surgical time $[25,35]$.

As proposed by Grupe and Warren [10], we conditioned the root surface by a scaling and root planning. The benefits of using root surface chemical modifiers are questioned and do not appear to result in increased root coverage [36].

We adapted the technique of laterally positioned flap extending the intra-sulcular incision up to 4 teeth adjacent to the gingival recession (teeth 41-45). This may contribute to a higher vascularization of the pedicle and to the surgery success because of its thickness $[15,35]$. The distal vertical relaxing incision contour has been designed with the aim of eliminating bone exposure of the donor area [10], preventing possible periodontal sequelae like bone dehiscence, gingival recession and periodontal pocket. Some studies have reported gingival recession of $1 \mathrm{~mm}$ or more in the donor area observed at 30 days after surgery tending to reduce in the first 6 months, and the possibility of bone dehiscence of 0.5 $\mathrm{mm}[14,31,32,37]$. The main reason for the loss of insertion of the donor area is the exposure of the alveolar bone by the displaced flap.

The contour of the pedicle created by the distal re- laxing incision has preserved over $1 \mathrm{~mm}$ of attached gingiva in tooth 46, essential for the maintenance of its periodontal health [38]. Also, this allowed the stabilization of a keratinized tissue at the tooth 45 cervical contour [34]. The new approach for laterally positioned flap used in this case contributed to the absence of surgical sequels over the 18 postoperative months $[15,25]$. Thus, we have not used surgical cement because of the tissue dissection underlying connective tissue of the free mucosa (undermining) to promote passive flap stabilization in the receptor area [11].

The results have shown full coverage of the exposed root in tooth 41 at different follow-up periods. The apparent tissue gain in the mesial region observed in the early healing stages and later, is a progressive reintegration of the grafted tissue called creeping reattachment and creeping attachment, respectively $[32,39,40]$.

Pfeifer and Heller [41] demonstrated in a pilot study that the full-thickness flap results in better root coverage for laterally positioned flap. The authors described a connective insertion and an epithelial adaptation of the graft to the root surface in cases treated with a full-thickness and partial-thickness flap, respectively. In the present study, the periodontal sulcus $\leq 3 \mathrm{~mm}$ was associated with gingival ischemia by the bottom compression in all sites, suggesting a possible new connective tissue insertion even in the surgically covered area, instead of a long junctional epithelium. The success of mucogingival surgeries comprises the increase of gingival dimensions, total or partial root coverage and esthetic improvement [14].

It is important to consider that the tissue of the laterally positioned graft covering the root surface has the same phenotype characteristics (Figure 8), and in these cases, it is essential an oral hygiene instruction associated to professional periodontal maintenance to achieve a best predictability in the long term.

The cases of a widespread unfavorable periodontal phenotype represent a major challenge in aesthetic periodontal reconstructive surgery [22]. We attribute the success of the surgical procedure not only to the surgical technique and the surgeon's skill, but mainly to the patient's commitment to follow all the recommendations and go to all monitoring and reassessment visits.

\section{Conclusion}

No accidents or surgical complications occurred during or after the procedure. The 18 months of postoperative follow-up could confirm the complete remission of dentinal hypersensitivity and total root coverage of the tooth 41 , and the aesthetic result was considered satisfactory by the patient. Based on the significant reduction of risks and morbidity associated with surgical procedures for root coverage, we conclude that the laterally positioned flap proposed in this study is a safe and feasible option for the surgical correction of single gingival recession in patients with unfavorable gingival phenotype. 


\section{References}

1. The American Academy of Periodontology (2001) Glossary of Periodontal Terms. ( $3^{\text {rd }}$ edn), Chicago.

2. Ericsson I, Lindhe $\mathrm{J}$ (1977) Lack of effect of trauma from occlusion on the recurrence of experimental periodontitis. $J$ Clin Periodontol 4: 115-127.

3. Wennström JL (1990) The significance of the width and thickness of the gingiva in orthodontic treatment. Dtsch Zahnarztl Z 45: 136-141.

4. Wennström JL (1996) Mucogingival considerations in orthodontic treatment. Semin Orthod 2: 46-54.

5. Kassab MM, Cohen RE (2003) The etiology and prevalence of gingival recession. J Am Dent Assoc 134: 220-225.

6. Rodier P (1990) Clinical research on the etiopathology of gingival recession. J Parodontol 9: 227-234.

7. Albandar JM, Kingman A (1999) Gingival recession, gingival bleeding, and dental calculus in adults 30 years of age and older in the United States, 1988-1994. J Periodontol 70: $30-43$.

8. Miller PD (1985) A classification of marginal tissue. Int $\mathrm{J}$ Periodontol Res Dent 5: 8-13.

9. Smith RG (1997) Gingival recession. Reappraisal of an enigmatic condition and a new index for monitoring. J Clin Periodontol 24: 201-205.

10. Grupe HE, Warren RF (1956) Repair of gingival defects by a sliding flap operation. J Periodontol 27: 92-95.

11. Staffileno H, Levy S, Gargiulo A (1966) Histologic study of cellular mobilization and repair following a periosteal retention operation via Split thickness mucogingival flap surgery. J Periodontol 37: 117-131.

12. Mattout $P$, Mattout $C$, Rousseau P, Franquin JC (1987) Histological study of healing of a laterally positioned flap: apropos of a case. J Parodontol 6: 101-109.

13. Chambrone L, Chambrone D, Pustiglioni FE, Chambrone LA, Lima LA (2008) Can subepithelial connective tissue grafts be considered the gold standard procedure in the treatment of Miller Class I and II recession-type defects? J Dent 36: 659-671.

14. Wennström JL (1996) Mucogingival therapy. Ann Periodontol 1: 671-701.

15. Bouchard P, Malet J, Borghetti A (2001) Decision-making in aesthetics: root coverage revisited. Periodontol 27: 97-120.

16. Beck JD, Löe H (1993) Epidemiological principles in studying periodontal diseases. Periodontol 2: 34-45.

17. Ainamo J, Bay I (1975) Problems and proposals for recording gingivitis and plaque. Int Dent J 25: 229-235.

18. Van der Weijden GA, Timmerman MF, Nijboer A, Reijerse E, Van der Velden U (1994) Comparison of different approaches to assess bleeding on probing as indicators of gingivitis. J Clin Periodontol 21: 589-594.

19. Mühlemann HR, Son S (1971) Gingival sulcus bleeding--a leading symptom in initial gingivitis. Helv Odontol Acta 15: 107-113.

20. Greenberg J, Laster L, Listgarten MA (1976) Transgingival probing as a potential estimator of alveolar bone level. J Periodontol 47: 514-517.

21. Benqué E, Brunel G, Gineste M, Colin L, Duffort JF Les re'cessions gingivales. J Periodontol 2: 207-241.

22. Maynard JG Jr, Wilson RD (1980) Diagnosis and management of mucogingival problems in children. Dent Clin North Am 24: 683-703.
23. Löst C (1984) Depth of alveolar bone dehiscences in relation to gingival recessions. J Clin Periodontol 11: 583-589.

24. Armitage GC (2004) Periodontal diagnoses and classification of periodontal diseases. Periodontol 34: 9-21.

25. Greenstein G, Greenstein B, Cavallaro J, Elian N, Tarnow D (2009) Flap advancement: practical techniques to attain tension-free primary closure. J Periodontol 80: 4-15.

26. Johal A, Katsaros C, Kiliaridis S, Leitao P, Rosa M, et al. (2013) State of the science on controversial topics: orthodontic therapy and gingival recession (a report of the Angle Society of Europe 2013 meeting). Prog Orthod 14: 16.

27. Slot DE, Berchier CE, Addy M, Van der Velden U, Van der Weijden GA (2013) The effect of chlorhexidine dentifrice or gel on plaque, clinical parameters of gingival inflammation and tooth discoloration: a systematic review. Int J Dent Hyg 12: $25-35$.

28. Supranoto SC, Slot DE, Addy M, Van der Weijden GA (2015) The effect of chlorhexidine dentifrice or gel versus chlorhexidine mouthwash on plaque, gingivitis, bleeding and tooth discoloration: a systematic review. Int J Dent Hyg 13: 83-92.

29. da Costa LF, Amaral CD, Barbirato DD, Leão AT, Fogacci MF (2017) Chlorhexidine mouthwash as an adjunct to mechanical therapy in chronic periodontitis: A meta-analysis. J Am Dent Assoc.

30. Hürzeler MB, Weng D (1999) Functional and esthetic outcome enhancement of periodontal surgery by application of plasticsurgery principles. Int $\mathrm{J}$ Periodontics Restorative Dent 19: 36-43.

31. Guinard EA, Caffesse RG (1978) Treatment of localized gingival recessions. Part I. Lateral sliding flap. J Periodontol 49: 351-356.

32. Caffesse RG, Guinard EA (1980) Treatment of localized gingival recessions. Part IV. Results after three years. J Periodontol 51: 167-170.

33. Patel M, Nixon PJ, Chan MF (2011) Gingival recession: part 2. Surgical management using pedicle grafts. Br Dent $\mathrm{J}$ 211: 315-319.

34. Baker $P$ (2002) The management of gingival recession. Dent Update 29: 114-120.

35. Chambrone L, Sukekava F, Araújo MG, Pustiglioni FE, Chambrone LA, et al. (2010) Root-coverage procedures for the treatment of localized recession-type defects: a Cochrane systematic review. J Periodontol 81: 452-478.

36. Mariotti A (2003) Efficacy of chemical root surface modifiers in the treatment of periodontal disease. A systematic review. Ann Periodontol 8: 205-226.

37. (1996) Consensus report. Mucogingival therapy. Ann Periodontol 1: 702-706.

38. Lang NP, Löe H (1972) The relationship between the width of keratinized gingiva and gingival health. J Periodontol 43: 623-627.

39. Glickman I, Smulow JB, O'brien T, Tannen R (1963) Healing of the periodontium following mucogingival surgery. Oral Surg Oral Med Oral Pathol 16: 530-538.

40. Trombelli $L$ (1999) Periodontal regeneration in gingival recession defects. Periodontol 19: 138-150.

41. Pfeifer JS, Heller R (1971) Histologic evaluation of full and partial thickness lateral repositioned flaps: a pilot study. J Periodontol 42: 331-333.
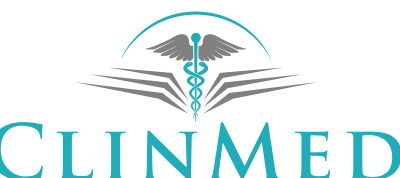

INTERNATIONAL LIBRARY 